\title{
The introduction of phytiatry in universities as a distinct science, is a primary necessity for food security and modernization of global agriculture
}

\begin{abstract}
Scientifically qualified specialists able to work as Phytiatry (plant medicine) doctors are needed world-wide. However, phytiatry as a distinct University science has not been introduced so far. Unfortunately, its establishment was unsuccessful regardless of the timeless scientific efforts. Obviously, Phytiatry doctors will be able to follow careers as diagnosticians in plant health clinics, as crop consultants, plant pest inspectors, extension specialists, phyto pharmaceutical industry consultants, small business owners, applied research specialists for research institutes, or other plant health professionals. Our proposal constitutes a new proposal for a universal effort to introduce Phytiatry in universities, so to elevate and uniform educational status and specialization, consequently creating a new attractive profession of Phytiatry doctors. Phytiatry, as a University multidisciplinary science could include several agronomical and biological scientific disciplines, having as core phytopathology, entomology and nematology, weed science and phyto pharmacy, soil management and fertilizers etc. to install a five-year University course as stands for Veterinary Medicine internationally, offering to the future plant doctors the opportunity of obtaining the necessary skills and qualifications starting from an undergraduate level.
\end{abstract}

Volume 2 Issue 3 - 2018

\author{
Eleftherios CTjamos \\ Department of Plant Pathology, President of the Hellenic \\ Society of Phytiatry, Greece
}

Correspondence: Eleftherios CTjamos, Emeritus Professor in Plant Pathology, Agricultural University of Athens, 75 lera odos str, I I855, Greece, Email tjamatika@gmail.com

Received: April 26, 2017| Published: June 05, 2018

\section{Introduction}

In an era of super specialization qualified scientists with a broad phytiatry (plant medicine) educational background able to work as Phytiatry doctors are undoubtedly missing. So diagnosticians for first aid plant clinic labs, field, garden or forest service with a distinct plant doctors' degree are really unavailable. Similarly plant pest consultants or inspectors working as practitioners and several other relative professions to cover needs as pharmaceutical industry consultants, small business owners, applied research specialists for research institutes or other plant health professionals, derive from various scientific disciplines with dramatically consequences for world agriculture. This could be corrected through new university courses offering the opportunity of obtaining the necessary skills and qualifications from an undergraduate level. It is oxymoron when medicine in humans and veterinary medicine in animals support extensive specializations for their efficient and qualitative application, Phytiatry, so significant for food security and for preventing vast income losses in world agriculture, caused by diseases and pests, has not yet been introduced in agricultural sciences and be recognised internationally. Indeed, nowadays agronomists, horticulturists, biologists, microbiologists, technologists in agriculture, plant clinic trained specialists, or postgraduate scientists in crop protection, are mainly those who deal with plant protection management world-wide.

However, professionals such as real phytiatry doctors can not originate from a general university education or even not university educated people with training in seminars and expecting to cope with acute and extensive problems of plant pest management and food security worldwide. Although postgraduate studies have been introduced in universities using the terms Plant Protection, Plant Medicine, Plant Health or Phytiatry, the time has come to establish undergraduate studies by introducing Phytiatry as a distinct university science. Phytiatry, as a separate university multidisciplinary science, which could include several agronomical and biological scientific disciplines, having as core phytopathology, entomology and nematology, weed science and phyto pharmacy, soil management and fertilizers, plant breeding etc. to create a five-year university course as stands for Veterinary Medicine world-wide. This proposal analyses the arguments and indicates the necessary steps to be taken for an updated groundbreaking campaign of overthrowing the prevailing lack of university specialized plant doctors. It strongly supports an international initiative for convincing universities to introduce Phytiatry. This pioneer effort will transform the educational status of phytiatry doctors and fill up the gap of so needed qualified scientists in world agriculture. ${ }^{1,2}$

\section{Conceptual content and use of the terms}

\section{Phytiatry, phytomedicine, fitoiatria, plant medicine, plant health and plant protection}

As agriculture, microbiology, chemistry and other relevant sciences were evolving several academicians introduced and used terms parallel or equivalent to medicine in humans and veterinary medicine in animals to demonstrate that plant diseases and pests have similarities in origin, cause, diagnosis and management and should be equally treated. Regardless of the existence of hundreds of international scientific societies devoted to the plant protection or to health sciences, currently relevant societies use also the terms Phytiatry or Plant Medicine such as in Germany, Italy, Greece and Switzerland. In Germany they introduce the term Phytomedicine for several years now. Indeed, today the Deutsche Phytomedizinische Gesellschaft (German Phytomedical Society-currently called the German Scientific Society for Plant Protection and Plant Health) is the largest scientific association in plant production in Germany. The 
members of the Society are mostly professionals within the entire field of phytomedizine. As phytomedizine they define the science of biotic or abiotic plant disorders, their diagnosis, management and control. It deals with all infectious agents that attack plants, and also covers damage caused to crops by pests, diseases and weeds. Under this definition, they additionally include abiotic disorders such as drought, frost, flooding, poor drainage, nutrient deficiency, salt deposition or misuse or overuse of pesticides. Notwithstanding, the term Phytomedizine is used in Germany to name relative departments and University textbook for several years now. ${ }^{3-11}$ In Italy they introduced and occasionally used the term Fitoiatria (equivalent to Phytiatry). The term Fitoiatria (originating from the Greek word Phytiatry) was introduced to describe the scientific discipline that includes techniques and procedures, aimed at curbing or protecting plants. The study and application of the methods of prevention, care and fighting plant diseases is the current definition. It integrates knowledge from the plant pathology, entomology, anatomy and plant physiology, physics and chemistry and not least, the agricultural techniques. Prof. M. Salerno in Bari introduced the term Medicina delle piante (Plant medicine), term which has being also adopted by other Italian Universities such as Firenze and Bologna offering Master degrees in Medicina delle piante. ${ }^{12}$ Till recently the Italian Society of Phytiatry there was also operating (Societa Italiana di Fitoiatria). In USA the term Plant Medicine was introduced by late Prof. Agrios ${ }^{13}$ of the University of Florida for postgraduate studies. The Plant Medicine Program started in 1999. We note that Prof. Agrios, ${ }^{13}$ did not use the term plant protection but introduce the term Plant Medicine. Similarly, the University of Nebraska ${ }^{14}$ introduced a Doctorate degree in Plant Health and not in Plant Protection to train practitioners rather than researchers in entomology, agronomy, plant pathology and soil science. ${ }^{14,15}$ In France or in French speaking countries (e.g. Canada, Belgium, Morocco, Algeria and Tunisia) the term Phytiatrie (also originating from the Greek term Phytiatry) is used, while Msc projects are offered with the name Phytiatrie and Phytopharmacie. Although, dictionaries indicate that Phytiatrie is Phytopathology in several cases the term is applicable to Phytiatry too. In Switzerland the Swiss Society of Phytiatry ${ }^{16}$ stimulates a consolidated exchange of information between experts in research, development and extension work. This renders the society an ideal meeting-place for specialists in phytopathology, entomology and weed science, helping them to establish contacts between the different disciplines of phytomedicine and to mutually profit from their colleagues' experience. Obviously they use the term Phytomedicine in parallel with the term Phytiatry. ${ }^{16}$ In Greece the Hellenic Society of Phytiatry ${ }^{17}$ has proposed the introduction of Phytiatry as a separate field of plant health sciences with the name Plant Medicine or Phytiatry and analogous to Veterinary Medicine. This initiative was justified by the apparent lack of inspiration and interest of candidate students to study the field of plant pathology, due to the uncertainty in obtaining future jobs (only research centers and university departments offer limited job opportunities) and the lack of attractiveness of this important discipline. This necessitates a revolution in educating students in various plant health disciplines. Thus, the society strongly supports the idea of educating scientists in the field of Phytiatry since several scattered sciences dealing with plant health will come closer and create undergraduate programs for phytiatry doctors of preferably a five-year duration. Besides, members of the Society contributed in developing a common master degree in Plant Medicine with other European countries, while the University of Thessaly has introduced a Masters Degree in Phytiatry. Neither of them used the term Plant Protection. ${ }^{17}$ In Spain the Spanish Association of Plant Health (AESaVe) created an open scientific society committed to promote plant health as a specialized profession in Spain through enhancing the need for specific training at Spanish Universities on plant health disciplines, while at the same time enhancing the perception by society of the critical role played by plant health on agro-forestry sustainability and food security. As I am going to elaborate in the next paragraphs the term plant health has a restricted meaning, while the society is referring to university courses in Phytiatry. ${ }^{18}$

\section{Plant protection and plant health: selected arguments clarifying the occasionally misleading or inadequate terms used to replace the term plant medicine}

The introduction of the terms plant or crop protection was initiated by international organizations to impose regulations concerning plant material movement, legislations in protecting countries from the dispersal of quarantine pests and diseases and rules in circulating and registering the pharmaceutical products. These terms have been since then erroneously used to cover all aspects of Phytiatry. However, according to the evolution of the International Plant Protection Congresses (IPPC) the first IPPC was held in Louvain, Belgium in 1946 and up to 1979 they had focused mainly on presenting new means of controlling insects and carrying out discussion related to the chemical control of plant diseases. The IPPC Congress held in Washington, DC in 1979 was the first organized by a multidisciplinary group with emphasis on integrated pest management (IPM). IPPCs have provided a forum for plant protection scientists to communicate and discuss important problems and new discoveries related to crop losses due to pests and their management. Obviously this is just Applied Phytiatry (Plant Protection). Scientific views of academicians concerning differences among the terms have been expressed in Leuven, Belgium by late Prof. Van Assche $\mathrm{C}^{19}$ in Agro-Ecosystems. Analyzing the theoretical and applied concepts of chemical soil disinfestation he used the term of Plant Protection as part of the Phytiatry. We do also notice that the University of Leuven offers currently a course entitled Principles of Phytiatry and not in Plant Protection. ${ }^{19}$ The late Prof. Dekker, J. of the University of Wageningen redefining the concept of plant protection $\left(40^{\text {th }}\right.$ International Symposium on Phytopharmacy and Phytiatry Gent, Belgium, 1988) insisted that instead of Plant Protection, the terms Phytopharmacy and Phytiatry cover all aspects of Phytiatry including research and application. Unfortunately, currently the organizers of these symposia have changed the name to International Symposium on Crop Protection, possibly being "victims" of the overwhelming prevalence of the term plant protection.

\section{Current efforts and initiatives}

Clarifying the terms Phytiatry, Plant Protection, Plant health and focusing on Phytiatry (Plant medicine) we realize the necessity for the establishment of a discrete science at an undergraduate level and creating a new useful and attractive profession. So, a variety of concepts is analyzed by presenting arguments which emphasize the fundamental particularity of all sciences included in the Phytiatry and demonstrating the requirement for upgrading the education and specialization on basic and applied disciplines of Phytiatry at the undergraduate level. So, discrepancies among the terms Plant Health or Plant Protection are designated. It is stressed that these terms must be avoided when used as alternatives to Phytiatry sciences, since these concepts are narrow and applied occasionally erroneously. ${ }^{17}$ 
Indeed, Plant protection is a rather artificial-technical concept, coined out as a term related to the control of plant pests and diseases in a prophylactic manner. Generally, it deals with the use of chemical means, cultural practices or state regulations for pest control. Thus, plant protection refers mainly to the applied aspects of Phytiatry.

Plant health refers mainly to national or international rules and legislations for protecting safety of plant food, securing the health and quality status of crops, regulating the trade of plants and plant products supervising the sale and use of plant protection products, or pesticides and setting standards to monitor and control pesticide residues. Obviously, as the term Public health in humans covers a very small part of Medicine, similarly Plant Health is a limited part of Phytiatry. On the contrary the term Phytiatry as Medicine in humans, is directly correlated with all aspects of basic and applied topics of various multidisciplinary Phytiatry sciences. The sciences that deal with fundamental and applied research and implementation of methods, techniques and tools for the diagnosis, prevention, therapy, dispersal or protection from plant diseases and pests and generally management of plant pests and diseases. Apparently, includes also all measures and regulations concerning plant protection and plant health necessary to manage pests and pathogens. Consequently, the terms plant protection or plant health when compared or used instead of Phytiatry are not similar and broad enough to cover all aspects of the whole science of Phytiatry. In order to avoid the misunderstanding which has been created due to the use of term Plant Medicine by certain physicians, I propose the term Phytiatry as the most appropriate term already used in French, Italian and English and coincides with phyto medicine in German. ${ }^{17}$

\section{The scientific concepts of phytiatry and phytiatry- doctors}

Beyond any doubt modern Agriculture needs Phytiatry as a separate University science to create the distinct and independent new profession of phytiatry doctors. Indeed, modern agriculture needs Phytiatry doctors, who will be able to work in the labs but also, when invited, to be able to visit the fields, the orchards or the glass houses to examine plant health problems, to attend symptom expression, to diagnose the causes and identify pests and weeds, to examine problems of plant nutrition, soil fertility and suggest the necessary measures. Phytiatry doctors, who will detect the new problems, communicate with plant clinics; transfer to the agricultural practice the new research results through a private or state controlled extension service.

Late Prof. Agrios ${ }^{20}$ in his arguments for establishing Plant Medicine in the University of Florida stressed emphatically that "plants, are affected by numerous abiotic ailments, such as nutritional deficiencies; nutrient and other mineral toxicities; meteorological extremes in temperature, moisture, and light; adverse soil $\mathrm{pH}$ and salinity; toxic soil and air pollutants; soil compaction; improper cultural practices; and so on. Plants, in addition to being attacked by fungi, bacteria, viruses and nematodes, are also attacked by many other biotic causes of injury and disease, such as insects, mites, slugs, rodents and field mice, birds, deer, and other plants and parasitic algae; they also constantly compete with numerous weeds for space, water, nutrients, and light. How many plant pathologists, or other specialists, such as entomologists, agronomists, horticulturists, weed scientists, etc., are qualified by their training to solve problems caused by any of the factors other than those they specialized in? In my opinion, hardly any! Oh yes, some extension specialists, once on the job, learn on their own or from colleagues how to deal with these problems, if they have to. But so do the farmers. That is not the training one should expect from an "expert" on whose diagnosis and recommendation one entrusts one's crop and livelihood" ${ }^{20}$ The lack of generalist plant medicine doctors led him at the University of Florida to propose and establish the "Doctor of Plant Medicine" professional doctorate degree program using as models the human medicine MD program that produces doctors for humans and the veterinary (animal) medicine DVM program that produces animal doctors, justifying his proposal that neither the MD nor the DVM program gives a $\mathrm{PhD}$, nor expects the students to do research or to write a dissertation. Instead, both MD and DVM students learn how to diagnose as many as possible of the abiotic and biotic ailments that affect their respectively, and to provide recommendations for their treatment and management. And, upon graduation, these students receive the professional doctorate degrees Doctor of Medicine (MD) or Doctor of Veterinary Medicine (DVM), respectively. Regardless of the importance and necessity of this suggestion I personally feel that we have to start from the undergraduate level since among other disadvantages $\mathrm{PhD}$. in plant medicine is a money consuming and a long-term procedure. ${ }^{13}$

\section{The role of phytiatry doctors in comparison with the so-called plant doctors in disease and pest diagnosis}

Guessing the cause of a plant disease either from a superficial oral examination or through a digital image does not mean professional diagnosis. Unfortunately, this is regular practice followed by the great majority of the so-called plant doctors, who are trying to identify pest and diseases through a simple look without using any technical help or diagnostic tool or laboratory equipment. Images are unsuitable for diagnostic purposes and for management recommendations particularly for soil borne pathogens and pests and Abiotic disorders but pseudo-phytiatry doctors are regularly following these practices. Of course, several diseases provide information for the agent appearing with distinct symptoms and signs (e.g., rusts, powdery mildews etc.) can readily be identified from a photograph and appropriate management recommendations can be made. However, diagnosis through photographs is not a scientifically acceptable attitude for phytiatry doctors. So, the digital images are just an auxiliary tool for experienced diagnosticians before making a timely and correct diagnosis. Unfortunately, currently agronomists, horticulturists, biologists etc. usually acquire much generalized and limited university knowledge related to control of pests and plant diseases, so normally in many specialized cases operate with unjustifiable amateurism. Many consider themselves as specialists but the so called plant doctors; they are not scientifically reliable and eligible for the job. Besides, they are not available at the actual sites of plant production today. Although several people consider that services in applied phytiatry could be still based on general crop production knowledge, simply increased and specialized through the everyday practice and seminars, empirical plant doctors in the $21^{\text {st }}$ century are not accepted. Indeed, this service is occasionally based on inadequate superficial knowledge, on empirical information or even on unethical attitude of practitioners who are unable to deal with phytiatric problems arising from wrong diagnoses, failure to diagnose, inability to distinguish between the causes of similar symptoms, or full ignorance of the nature and biology of the pathogens the quarantine pathogens and pests. This leads to tragic diagnosis and proposals for management with negative financial and environmental impacts. Obviously lack of phytiatry doctors allows amateurism to prevail 
with unqualified scientists who are unable to distinguish the causes of diseases, pest infections and plant stress effects, appearing with similar symptomatology. Notwithstanding, plant pathologists, entomologists, weed science and plant stress specialists cover partially the needs of application since they are very specialized, thus, suitable to work in research centers and Universities. So, a new scientist has to fill the existing gap Phytiatry doctors combining these scientific disciplines in one practical level.

\section{Trained plant doctors, plant clinics world-wide and appropriate education}

Plant clinics world-wide run by universities, research institutes or private companies can substantially contribute to the scientifically disease and pest diagnosis when scientists of different specializations can cover the diversified needs of applied phytiatry. Obviously these institutions are unable to cover the enormous and complicated needs for specialists in the actual sites of practicing agriculture. So, the general practitioners able to deal with various problems on the spot are really missing, since this can only be achieved by university educated phytiatry doctors. Indeed, I appreciate the global effort of Plant wise developed and led by CABI to increase food security and improve rural livelihoods by reducing crop losses. A real precious initiative for improving people's lives by providing information and applying scientific expertise to solve phytiatry problems in agriculture and the environment by enlarging a global knowledge bank, bringing together and sharing existing and new information on plant health. Additionally, Plant wise project, links thousands of plant clinics in more than 49 countries. On a world-wide scale, almost 500 million smallholder farmers are feeding two thirds of the global population. CABI offers training courses on how to set up, run and document clinics. Plant doctors make recommendations for farmers on plant care in the same way a health center does for humans.$^{20}$ Independently of their useful contribution to several countries around the globe my belief is that plant doctors must be graduates of phytiatry departments and not scientists of questionable and inadequate scientific training.

\section{Postgraduate studies in phytiatry: advantages and disadvantages}

Selected cases of $\mathrm{PhD}$ doctor in plant medicine

How the case has developed so far, first steps world-wide

\section{Universities of Florida and Nebraska in USA:}

\section{University of Florida}

I believe that late Prof. George Agrios, ${ }^{21}$ excellent statement concerning his arguments and efforts to establish Doctor in Plant medicine is the first important written text in activating the academicians for introducing the name doctor in plant medicine and not doctor in Plant Protection..$^{21}$ Based on his personal experience to diagnose diseases of plants caused by various pathogens and to provide recommendations for their management and to the inability of the existing plant protection postgraduate studies leading currently so many of the young plant pathologists etc. to study molecular plant pathology that they may be excellent for in-depth research but know little about practical plant pathology. Even the practically oriented plant pathologists, however, are limited by their training in the areas mentioned above: fungal, bacterial, and viral maybe, nematode diseases. Prof. Agrios ${ }^{21}$ considered that the education and training needed to produce general practitioner plant doctors (scientists who can diagnose and provide control or management recommendations about as many as possible of the biotic and abiotic diseases and injuries affecting plants is missing world-wide. So their effort to offer high standards education and training for the professional doctorate degree in Plant Medicine in the "Doctor of Plant Medicine"15 (DPM) program of the University of Florida.

\section{University of Nebraska}

Prof. Anna Vidaver thinking along similar lines with Florida introduced the Doctorate Degree in Plant Health in 2008 in the University of Lincoln, Nebraska. ${ }^{17}$ Her idea was to offer a degree considered to be the rough equivalent of a general practitioner degree in medicine or a veterinary degree in animal health, since there wasn't really anything like that in the plant sciences. Their doctorate in plant health was considered as the second program of its kind in USA, following the Doctorate in Plant Medicine of the University of Florida. Her fundamental argument which made the degree unique was that all the other three or four-year degrees are focused in areas of research. This movement came about as a result from requests by crop consultants and representatives from various industries to start the program after finding many graduates they hired who had a traditional disciplinary focus didn't have a wide breadth of practical skills. Prof. Vidaver underlined that plant diseases, insects and drought are among the problems that can afflict agriculture, and there are few people that have broad knowledge or training to combat all of these.

\section{Other universities}

Now moving to other Universities around the globe we can identify those which collaborate with the University of Florida. It seems that these Universities have a tradition on plant medicine departments and are who tried to get involved with a doctor degree in plant medicine.

\section{Below are some of them which offer already first bachelor's degree in plant medicine:}

In Japan, during 2014 the Hosei University established the Department of Clinical Plant Science. The main offered courses are focused on four major topics including General Clinical Plant Science, Food Safety: Plant Disease Diagnosis and Plant Medical System. Below are given details concerning the content of these interesting topics introduced by one of pioneer Universities around the globe.

General clinical plant science: Students will understand the outline of a new field called clinical plant science to learn about concept, technology, and its relationship with food safety, environmental preservation and the social economy. Students will also attempt to find the basic idea of clinical plant science by reviewing the recent phenomena of plant disease.

Food safety: There is high interest in the food safety issue including residual agricultural chemicals, mycotoxin pollution, cadmium pollution, etc. We will discuss the current status and the future direction of food safety issues based on the quality control method and risk analysis of food hygiene.

Plant disease diagnosis: Students will understand accurate diagnosis methods through etiological cause observations of plant disease. They can acquire basic methods and procedures for diagnosing microorganism disease and insect or nematode damage, etc. These experiences and knowledge can become the foundation of an associate tree doctor or associate nature restoration promoter. 
Plant medical system: Students will understand each data base and expert systems used in diagnosing plants to investigate their utilization needs, possibilities and issues. Also we will look at the application of information technology in agriculture

\section{In South Korea, Chungbuk National University ${ }^{15}$}

In Taiwan National Chiayi University ${ }^{15}$ Four years course in Plant medicine. National Pingtung University of Science and Technology. ${ }^{15}$ The department was founded in 1975, and was named the Department of Plant Protection. In 1998, the Department switched from a 2-year to a 4-year program of study leading to the degree of Bachelor of Science. They also offer a master's program. This department requires that its graduates acquire a strong knowledge of plant protection, with a focus on the infection or infestation of plant diseases, weeds, insects and other pests. In addition to promoting the professional status of its students, this department seeks to imbue them with strong practical training, especially in diagnosis of plant diseases and insect pests, quarantine inspection, and integrated pest management.

\section{In European Union}

Italy master's degree in Medicina delle piante in the Universities of Bari, Firenze and Bologna

\section{Tempus Project among several EU and Balkan countries in Plant Medicine}

\section{University of Thessaly Greece, Phytiatry and Environment}

According to my long lasting experience M.Sc. or $\mathrm{PhD}$ in so called Crop Protection programs are generally inadequate to meet specific qualifications since their graduates are unable to become practitioner plant doctors and proceed in properly identifying fungal, bacterial, viral and nematode disease and pests and recognize abiotic disorders. Furthermore, the number of those students following doctorate programs in Plant Medicine of the Universities of Florida and Nebraska is dramatically small and and of high standards to deal with very specific jobs and not to make a revolution by covering the needs of a diversified market worldwide.

\section{Graduate studies in phytiatry: the right time for the necessary movement leading to a real solution}

What is the current situation? Today there is a scientific gap in Phytiatry sciences at an undergraduate level. Indeed, there are very few Universities offering first University degree, such as Bachelor in Plant Protection and Integrated Pest Management or even in Phytiatry (Plant Medicine). I can mention the most well-known of them:

California State University - Fresno in Plant Protection

Serbia, Belgrade- in Phytiatry

Bulgaria, Plovdiv- in Plant Protection

In Japan, Hosei University, Department of Clinical Plant Science aims at fostering "plant doctors.

\section{In South Korea, Chungbuk National University. ${ }^{15}$}

In Taiwan National Chiayi University ${ }^{15}$ Four years course in Plant medicine leading to the degree of Bachelor of Science. Agricultural sciences are continuously modernized by adding a plethora of various new scientific courses, which help Agronomy to introduce new distinct disciplines. These sciences are gradually separated from classical Agronomy and create relative professions in various scientific fields. Among others, Crop Science, Animal husbandry, Food science, Biotechnology in agriculture, Agricultural engineering, Agricultural economics and so on are the most common. Unfortunately, as for Phytiatry these changes still have not taken into account its importance for extensively establishing Phytiatry as a new university science around the globe. However, thousands of students in Agricultural Universities are still obliged to take so many diversified courses without focusing on creating useful and attractive profession. Thus, several graduates of other disciplines are trying to combat problems of the applied phytiatry. Regardless of the enormous differences existing among diversified agricultures worldwide the principles and the problems are similar everywhere. So, the contribution of phytiatry doctors is a universal necessity, since it is difficult and risky to confront the problems with unqualified scientists. I do believe that diagnosis taking place in well organized plant clinics is the final step of diagnosis. They are however very first stages of diagnosis which must be based on the education and experience of the phytiatry doctors taking place in centers located in close vicinity to the agricultural enterprises so to be able to have also the ability of personal surveys (fields, gardens, orchards, forests). ${ }^{2}$

\section{Scientific courses in phytiatry}

Over 40 different scientific courses listed below could be included in the interdisciplinary science of Phytiatry within a five years' curriculum.

\section{Phytiatric sciences}

Phyto pathological Mycology, Plant Bacteriology, Plant Virology, Molecular Plant Pathology, Plant disease Epidemiology, Agricultural Entomology, Agricultural Zoology, Nematology, Weed Science, Phyto pharmacy, Breeding for disease and pest resistance, Principles of plant disease and Pest Diagnosis, Plant Protection Strategies, Identification of new diseases, pests and weeds, Disease and Pest Monitoring, Molecular Biology, Biotechnology, Eco toxicology, Environmental Protection, Plant Physiology and Biochemistry, Plant Breeding Selection for controlling diseases and pests.

\section{Agronomic sciences}

Basic knowledge of general and specific Pomology, Viticulture, Horticulture, Floriculture, General and Special Agriculture, Forestry, Farming systems. Soil Science, Soil management and Fertilizers, Multiplication of plant breeding, Ecology and landscape architecture, Communication and information, Socio-economic impact of applied plant medicine, Quality production, Consumer protection, Production Systems, Stored-Product Protection, Harvest Processing, etc.

\section{International alert by American Phytopathological Society (APS) and British Society for Plant Pathology (BSPP)}

Alarming reaction by British Society for Plant Pathology stating that Plant pathology has been lost completely or greatly reduced at 11 UK Universities, threatening Britain's ability to combat new diseases. Plant pathology education in Britain needs to be revived, to reverse the decline in expertise and to give farmers and foresters better ways of controlling these diseases. The British Society for Plant Pathology ${ }^{22}$ in 
November 2012, pointed out that the shortage of plant disease experts threatens tree and crop health. A press release highlights the impact of the loss of skills and expertise in plant pathology. Plant pathology has been lost completely or greatly reduced at 11 universities and only 1 in 7 universities now provide practical classes in plant pathology. This threatens Britain's ability to combat new diseases of trees and crop as they show a serious decline in teaching and research on plant diseases in British universities and colleges. For example, University of Bristol, has appointed very few plant pathologists in the last 20 years. Many of those lecturers who remain are aged over 50 . There are now very few UK experts left in diseases of trees and vegetables. Plant pathology education in Britain needs to be revived, to reverse the decline in expertise and to give farmers and foresters better ways of controlling these diseases Campaign of British Society for Plant Pathology Become a plant doctor but they mean plant pathologist. We need well trained scientists and specialists to protect the vital food and crops we need worldwide Teaching students to recognize a few common plant diseases isn't good enough. If we truly want food security, we need to invest in the next generation of plant pathologists. So they have the knowledge and skills to identify and treat existing and new diseases. $\underline{22}$ American Phyto pathological Society(APS) ${ }^{23}$ produced and provides alarming youtube videos to emphasize the emerging need for plant doctors. ${ }^{23}$ But both the British and the Americans are wrongly considering as plant doctors plant pathologists only. Why two world top Phyto pathological Societies are trying to attract new students to become plant doctors? Because world agriculture needs real phytiatry doctors. It is however wrong asking youngsters to become phytiatry doctors without specifying what courses they have to attend at an undergraduate level. It is really wrong to try to identify needs and opportunities for developing skills and creating a recognized profession for plant health without clarifying from the beginning the educational channel and the curriculum of those who will become recognized and scientifically accepted phytiatry doctors. Plant health is something equivalent to public health (epidemics etc.) and many scientists could get involved. But a distinct science with a certain curriculum is needed. As we are unable to become medicine doctors by studying biology, microbiology, similarly we cannot become phytiatry doctors by studying just biology, microbiology, agronomy or horticulture and without studying Phytiatry as an undergraduate science.

\section{Actions}

The existing scientific societies using the terms Phytomedicine, Medicina delle piante, Plant medicine, Phytiatry or Plant Health apparently reflect their focusing on an attractive name for a new profession and a necessary science. But also highlight the role of Phytiatry in modern agriculture. Several people consider that services in applied Phytiatry could still be based on a general crop production knowledge, simply accumulated through a short-term training, or everyday practice and be backed by the pharmaceutical companies. To change this belief time, for common action by Universities, Academia, along with related Scientific Societies, the Private sector and Farmer unions, has come to play a substantial role in international cooperation and promote establishment of Phytiatry in Universities. From my longstanding experience I insist that postgraduate studies should come as a step next to undergraduate studies in Phytiatry. This movement needs the creation of a crucial mass of scientists, who believe in the role of Phytiatry for global action. Personally after presenting my thoughts in International scientific congresses and meetings (Rome Italy 2010,
Cyprus 2012, Valencia, Spain 2012, Istanbul, Turkey 2014, several times in Athens, Greece and in Berlin, Germany 2015), I would be willing to collaborate with all those who share the same thoughts, towards changing the current situation and offer real phytiatry doctors to world agriculture. If IAPPS and other relative societies with common interest endorse a direct action, personally I would be very pleased to host in Athens an International Congress in Phytiatry by inviting among others representatives of societies with the pioneer role of initiating discussions and create the basis for moving to the establishment of University Phytiatry world-wide.

\section{Conclusion}

Several strong arguments could be put forward in support of the introduction of Phytiatry in Universities as a distinct multidisciplinary science. Beyond those analytically presented the following are also essential: We do need a new attractive profession of Phytiatry doctors to fulfill the requirements of a modern and accurate identification of pests and diseases of plants in the global agriculture and cover modern requirements for plant disease and pest diagnosis. Phytiatry doctors could overcome problems related to similarities in symptom expression and be able to distinguish the complicated field and orchard cases of disease and pest recognition expressed with similar, thus misleading symptomatology. Phytiatry doctors could be trained to be able to contribute effectively in consulting farmers and inspecting for quarantine pests and pathogens to avoid their entrance and dispersal in regions, countries or continents. Phytiatry doctors could be able to suggest suitable pest management, to introduce disease and pest forecasting/risk assessment models, to contribute to best pesticide selection for securing effectiveness and food safety. Phytiatry doctors could be able to deal with the complicated and so costly problems of postharvest Phytiatry so common in modern agriculture. Phytiatry doctors could be able to deal with the impact of mycotoxins on food safety, food quality and world trade and suggest measures for management of mycotoxigenic fungi. Phytiatry doctors could be able to provide appropriate plant nutrition instructions, to secure best plant growth related to crop health. Phytiatry doctors able to guide the farmers in producing quality products both for human consumption and animal feed. Phytiatry doctors could be able to contribute in protecting agricultural environment and instruct farmers to take care of their farms, the agricultural environment and their personal health. Phytiatry doctors could be able to contribute in reducing unjustifiable expenses or high costs in crop production, through accurate diagnosis, best selection of measures and appropriate timing in application. Gardening and landscape architecture, money consuming and important world-wide, need the phytiatry doctors. Phytiatry doctors could be also able to work as leaders in plant clinics since they will be able to get experience on prevailing common or even rare diseases and pests of a cultivation (s) in their region. Phytiatry doctors could be also able to work for large municipalities which will realize that they need to have a phytiatry doctor in residence or on a retainer who will advise them on the nature, cause, and management of the various diseases and pests affecting turf, flower beds, shrubs and trees in city parks, city building grounds, and along streets. Phytiatry doctors could be also able to have employment opportunities for many different, challenging and well-paying jobs that generally, with a few exceptions, appear to be much better than are job opportunities available for Master degrees in plant protections. Undoubtedly University Florida's initiative as necessity to cover serious professional gaps in Phytiatry and as a decision of using the term Plant medicine instead of Plant 
protection (imposed internationally by those who wanted to focus on chemical control) was a very substantial and of high level step securing high educational quality and offering precious experience to the students. However, I am afraid that this was not a general and profitable scientific approach to become Phytiatry doctor by studying 8-10 years instead of entering directly the discipline of Phytiatry. Similarly, a graduate Doctor of Plant Health project in Nebraska ${ }^{14}$ said that he had previously received his Bachelor of Science (B.S.) in Horticulture (2007), Master 's (M.S.) in Entomology (2009), and his D.P.H. (2014) from the University of Nebraska ${ }^{14}$-Lincoln. This means that this graduate spent at least 10 years to become eligible to work as Phytiatry doctor. Since veterinary medicine doctors are not obliged to study relative sciences before becoming animal doctors, I consider that phytiatry doctors are not obliged to do so to become professionals in Phytiatry. I consider that the term plant protection should be used as a restricted one referring to the management of plant diseases and pests thus consisting an applied part of Phytiatry. I also criticize those academicians, who did not insist in imposing Phytiatry (Plant medicine) at an undergraduate level, although they were the pioneers of introducing the term. I also disagree with those who did not dare, as George Agrios ${ }^{21}$ did, to move ahead, propose and operate courses in Phytiatry. Whom are they afraid off and accept alternative terms - Sanidad or Plant Health-not covering the full meaning of Phytiatry. Among others by introducing the term Phytiatry as a distinct university science we avoid the so called plant doctors who perpetuate amateurism with so destructive consequences for world agriculture. I also consider $\mathrm{PhD}$ in Plant Medicine as a high level education obviously needed for special cases but it is very costly and extremely time consuming procedure to obtain the degree of plant medicine doctor.

\section{Acknowledgements}

None.

\section{Conflict of interest}

Author declares that there is no conflict of interest.

\section{References}

1. Tjamos EC. Phytiatry: priorities and challenges in the Mediterranean basin and worldwide at the 21st century. Petria. 2010;20(2):67-633.

2. Tjamos EC. Letter to the Editor: Establishing a New Science in Universities. Phytopathology News. 2010;44(05).

3. Feldmann F. Die Zusammensetzung der Mitglieder der DPG. Phytomedizin. 2004;34 (3):41-46.
4. Grossmann, F. The concept of phytomedicine. Indian Phytopathology. $1971 ; 24: 247-257$

5. Blaich R. Hoffmann GM, Nienhaus F, Poehling HM, et al. Lehrbuch der Phytomedizin, $3^{\text {rd }}$ edition. Blackwell Wissenschafts Verlag. 1994;146(56):766.

6. Hallmann JA. Quadt-Hallmann A, von Tiedemann. Phytomedizin Grundwissen Bachelor. Ulmer Stuttgart UTB. 2007.

7. Hoffmann GMF, Nienhaus HM, Poehling F, et al. Lehrbuch der Phytomedizin, Auflage, Blackwell Verlag. Berlin; 1994.

8. Heitefuss R. Pflanzenschutz, Grundlagen der praktischen Phytomedizin 3. Auflage. Thieme Verlag Stuttgart. 2000.

9. Mühle E. Phytomedizin und Pflanzenschutz. Der Pflanzenarzt. 1967;20:115-118.

10. Staar G, Reinmuth E. Phytopathologie und Pflanzenschutz - Phytomedizin In: Klinkowski M. (Hrsg.): Grundlagen und allgemeine Probleme der. Phytopathologie und des Pflanzenschutzes. 1974;2(1):3-5.

11. Sucker U. Anfänge der modernen Phytomedizin. Mitt d Biol Bundesanstalt. $1998 ; 334$.

12. CLM Medicina delle Piante. 2014-2015

13. Agrios GN. Frontiers and challenges in plant pathology communications: presidential address at $83^{\text {rd }}$ APS annual meeting, St. Louis MO. Phytopathology. 1992;82:32-34.

14. Doctor of Plant Health University of Nebraska

15. The Doctor of Plant Medicine Degree Program. Website. The College of Agricultural and Life Sciences, University of Florida, Gainesville, Florida.

16. Swiss Society of Phytiatry.

17. Hellenic Society of Phytiatry.

18. Asociación Española De Sanidad Vegetal.

19. Van Assche C. Purpose, control and motivation of chemical soil disinfestation. Agro Ecosystems. 1974;1:107-116.

20. Plant wise

21. Agrios GN. The Doctor of Plant Medicine Program at the University of Florida: Growers, agricultural agencies, and industries need plant doctors. Plant Health Progress. 2001.

22. British Society of Plant Pathology.

23. The American Phytopathological Society. 